\title{
Study about Intergenerational Inheritance Question of Private Family in Quanzhou Under the Perspective of "Second Venture"
}

\author{
Linjing Chen \\ TSL School of Business and Information Technology \\ Quanzhou Normal University \\ Quanzhou, China \\ Sandy8685@126.com
}

\begin{abstract}
With the development of China's economy, great changes have taken place in the market environment, the traditional "quanzhou model" has been gradually began to can't adapt to the requirement of sustainable development of the modern enterprise, and realize the family business between generations is an important topic of the sustainable development of enterprises. The article analysis the opportunities and difficulties of intergenerational inheritance about private family of Quanzhou based on "second venture", and put forward the corresponding solution strategy.
\end{abstract}

Keywords-second venture; Quanzhou; private family enterprise; intergenerational inheritance

\section{INTRODUCTION}

After 30 years of development, private economy in Quanzhou made gratifying achievements from the enterprise overall quantity,size and so on, become one of the most active areas in private economy in China. But like other coastal developed areas , as the drastic of market internationalization and competition, the development of corporation in Quanzhou faced constraints more and more. How to faster strengths and circumvent weaknesses, adapt to the impact of the new economy, the transformation of the mode of development and realize the "second venture", become the sustainable economic development of Quanzhou corporation.

Family enterprises is currently a mainstream form of non-public enterprises in China, $90 \%$ is small and mediumsized enterprises, in which $80 \%$ is family enterprises, Quanzhou is especially rich in family enterprises, and the influence of Quanzhou economy is growing. According to statistics, only $30 \%$ of families in the United States can be a successful transition to the second generation, $12 \%$ to the third generation, only $3 \%$ can be passed to the fourth generation successfully. The private family enterprises of Quanzhou is developed continuously along with the reform and opening up, the first generation entrepreneurs are beginning to face retirement decision, at the same time, family enterprises is faced with the transfer of power and wealth, but because of many reasons, such as the successor to itself quality problem, clear property rights department, enterprise management problems such as lack of innovation consciousness, and so on, many family enterprises are faced with the difficulty of inheritance. So how to seize the opportunity of "second venture", settle well problems of private family enterprises succession is one of the key problems of enterprise sustainable development.

\section{OVERVIEW OF INTERGENERATIONAL INHERITANCE}

\section{A. The definition of intergenerational inheritance}

Heritage, means transmission, succeeded, undertake, follow innovation. Inheritance different with succession, inheritance generally refers to undertake good aspects, first pass than bearing, is a kind of active form, and the meaning of the innovation in the process of inheritance.

Intergenerational inheritance is the professional term in enterprise management discipline, more commonly used in family businesses. Refers to the family business leaders change process, taking between leader and the next successor for the common heritage of the process in tangible assets and intangible assets of enterprises.

\section{B. The content of intergenerational inheritance}

\section{1) Power and wealth}

Power and wealth is the core of the enterprises between generations. If there is no power, his successor, there is no control of the enterprise and decision-making; If there is no wealth, successor, lack the necessary condition for normal operation of the enterprise.

\section{2) Competitive advantage factors}

Competitive advantage is the core of the intergenerational inheritance. The success of the intergeneration inheritance is determined by a series of factors of competitive advantage. Competitive factors involved in all aspects of the family business management and operation, including product quality, brand, strategy, corporate culture and entrepreneurial spirit, etc., these competitive factors influence each other, complement each other ,forming a very large and complex system[1].

\section{The main mode of intergenerational inheritance}

Intergenerational inheritance mainly includes four patterns: the first is transferring the leadership from fathers to sons, the pattern of family enterprises grow cultivate successor very early, and lack of trust to the people outside the family. The second is near relatives inherited, that is ,with no children or children do not meet the conditions, considering the brothers and sisters and other close relatives. 
The third one is dynastic inheritance, pan family here refers to no real kinship, but through marriage, such as raising way to become a member of the family. The fourth is the professional manager succession, this is a new modern enterprise management mode, implements the "family control" and "principal-agent" compatibility[2].

\section{III. "SECOND VENTURE" PERSPECTIVE OF QUANZHOU PRIVATE FAMILY BUSINESS SUCCESSION PROBLEM}

\section{A. The development of private family enterprises in Quanzhou}

Family-owned businesses and family-based management are two different concepts, in some developed countries, the family business is the norm, such as the United States $90 \%$ of the enterprise is the family business. Family-owned enterprise refers to the enterprise organization that ownership or ownership of control belong to one or several families or families all, can and have the ownership or ownership of control transfer to the offspring in legal; and family-based management is a kind of phenomenon that refers to the family business ownership and management rights is unified, and take the family-based authoritarian leadership, enterprise most important posts by members of the family.

The development of private family enterprise in Quanzhou has the following features:

\section{1) More numbers but small size of enterprises}

There are 3.6 ten thousand private enterprises altogether in Quanzhou by 2009, in the city's 100 key enterprises, private enterprises accounted for 98 ( more than $90 \%$ of them are family enterprises), and these enterprises more focus on the traditional industry, including clothing, ceramics, sculpture, toys, food and so on, but the proportion of businesses operating income over one hundred million yuan less, most at an early stage of development. From the point of industrial structure, most of the content of enterprise technology level is low, and the product structure is mostly year. It is labor-intensive and export, to he characteristics of the enterprise which has more quantity but small scale.

\section{2) Simple linear unity form of organizational structure}

At present most of the family business in Quanzhou is middle and small-sized, management organization is relatively simple, most are simple linear unity form the structure of the organization, and is a paternalistic centralized management. The owners adapted the autocratic management mode, everything is decided by business owners, lack of scientific and democratic decision-making, so entrepreneurs directly affect the enterprise culture, the decision-making of the enterprise, the insight and grasp of the market information, etc., that is not conducive to the expansion of enterprise scale and strength enhancement.

\section{3) Property rights definition is not clear}

According to the end of 2009, the private enterprises in Quanzhou which the property ownership is not clear as high as $43.25 \%$, for external, the property owners is trusted follower of close family; but for internal, its property right definition is not clear. Abide by the habit of Quanzhou local practice, there is not a clear definition of property rights between the members of the family, so there will be some enterprises that the first big shareholder's more than $50 \%$ by direct or indirect. Some members of the family without property rights, but operate the enterprise actually.

4) Family-based management and professional manager system is not perfect

Family members involved in management of enterprise generally, and distribution of power or checks and balances as the link of genetic relationship, because lack of democratic decision-making mechanism, the family members occupy the important positon, that leads to crisis of confidence between owners and managers intangibly and form 'authoritarian parents' management, although many companies have restructured to limited liability company or joint stock limited company,but didn't change the internal property right structure, decision mechanism and the governance of the family really.

\section{B. The problems of succession process of Quanzhou private family enterprises}

1) the conflict between the second generation successor and parents' entrepreneurs

In 2012, Yu Ming Yang, the management professor of Jiaotong university,Shanghai, and his team investigated 182 family enterprises, which are outstanding and ranked the top three in the industries, and analyze 54 successors of family business of China, of them are the most representative. Results showed that $18 \%$ of the "second generation entrepreneurs" willing and active succession, $82 \%$ of the "replacement" don't want to, and not active succession, like as other college students to take an examination of civil servants, some ideal of the "rich second generation" was "officials", which to a certain extent, reflects the current situation of private family enterprises succession of Quanzhou. First of all, because of development pattern and the limitation of enterprise structure, many conflicts exits in enterpriser and the second generation successor, they regard complex relations net as stumbled and it is difficult to make; Second, the quality of some successor itself did not keep up with the requirements of enterprise, it is difficult to inherit the tradition, they are more willing to choose other career, and succession family enterprises is "alternative";Again, most of the family business is now belong to the sunset industry, to the attraction of the second generation is not high.

\section{2) Lack of succession planning}

At present, the private family enterprise of Quanzhou general lack of succession planning, which lead to family business successor step off the deep end or founder of family enterprises who left leader position but still not fully decentralization, then the pattern and rights allocation will have great changes, the struggle and conflict of founder and successor is inevitable, so can't make a strategic decision, influence the development of the enterprise in the future. 
3) Difficult to fusion between family enterprises and professional managers

Like the rest of the country, the family business of Quanzhou have a low probability of success in introduce professional managers.First is Quanzhou itself lack of talent, talent attraction is low.In 2008, according to city personnel bureau of Quanzhou statistics, in survey of the talent resources, the main managers of small and medium-sized private enterprises, only $26.17 \%$ of university programs and above degree, with technical secondary school and high school education accounted for $57.72 \%$, is a very small proportion of high-end talent. Due to the urban construction, enterprise management, culture, custom, concept for making proper use of personnel,social atmosphere and the restriction of various factors, the private enterprises of Quanzhou have higher turnover of talent.Only $7.9 \%$ of the talents want to stay at Quanzhou, but more select developed areas surrounding or domestic big cities, such as Xiamen. Followed, the family enterprise internal management mechanism caused direct trust between professional managers with his boss. On the one hand, family businesses don't trust without blood relationship, reluctant to let outsiders into the enterprise senior and master the core of the data; On the other hand the talent of professional managers can easily be buried, relative insiders, they are more likely to be doubt its loyalty and crowd out, also not reasonable guarantee their rights, it is difficult to blend in the family business culture.

4) Identity disorder between successor and enterprise old mutual

In the process of the inheritance of family enterprises, enterprises determine the successor, then entered run-in period between the successor and enterprise old mutual,their conflict is rooted in identity disorder and trust crisis. Successor, after all, no work with enterprise old mutual, so they not get the nod of enterprise old mutual in work style, work values, ability and so on, if the relationship didn't get timely and properly handled, is bound to affect the future development of the enterprise.

\section{The chance for private family enterprises of Quanzhou in "second venture"}

It si said that "the first generation carve out, the second generation maintain,the third generation destroy," seems to have become a common trajectory, most of Chinese family enterprises proves it, so how to effectively grasp the opportunity in second venture to reconstitution instead of implementation for business, is a key issue.

\section{1) "Second venture" helps cultivate responsibility of} successor

Most of the private family enterprise of Quanzhou are labor-intensive enterprises, combined with insufficient attraction to talents, it is difficult to attract the younger generation in Quanzhou, which caused a lot of the second generation refused to inherit. In this case, if forced to, it will cause the opposite effect."Second venture" provided to the successor a fresh choice to the place and the opportunity of the industry, improve them succession will, to cultivate successors sense of responsibility and commitment to the enterprise.

\section{2) "Second venture" helps cultivate entrepreneurship of} successor

Entrepreneurship is the important part of enterprises culture to private family enterprises, the continuation of the first generation entrepreneurship is directly related to success or failure to succession of family business,at present stage one of the biggest obstacles is the gap between two generations in the spirit. In "second venture" it can get rid of the constraint of the original practice completely, two generations join hands together in practice, can directly to cultivate entrepreneurship of successor.

\section{3) "Second venture" is conducive to establishing} authority of successor

In days of carve out, entrepreneurs rely on his own ability won a high degree of recognition and respect, and represents the enterprise culture.Therefore, it is hard to get rid of the shadow of their parents, the younger generation is difficult to establish his own authority. In the process of "Second venture", the successor have the opportunity to build their own team, playing the role as decision makers, so it easy to get recognition of all and is conducive to establishing authority of successor in the enterprise.

4) "Second venture" will be conducive to build the corporate network

Relationship is the intangible asset to an enterprise, and many studies have shown that the main reason of family businesses "doctrines rate" is difficult to transfer intangible assets directly. "Second venture" provide more opportunities of further relieve parents "relationship" to the successor, also gave them legal status to communicate with these "relationship", and expand contacts and fusion to the successor[3].

\section{SUCCESSION PROBLEMS COUNTERMEASURES OF PRIVATE FAMILY ENTERPRISES IN QUANZHOU UNDER THE PERSPECTIVE OF "SECOND VENTURE"}

\section{A. Establishes and implement strategies to intergenerational inheritance as soon as possible}

The choice of family business succession is a systematic project, it need for a relatively long time, the family business should planed and orderly the problem of selection and training successors of the formulation and implementation as soon as possible, this is helpful to realize the balance of power transition. Family business elite should not be considering the succession in the life cycle management faced retirement, but should let the successor to participate in the enterprise management in advance, and bu sure by other 
staffs step by step, completed the intergenerational inheritance successfully.

Intergenerational succession planning mainly divided into three steps:first, launch the succession plans to the inheritance of decision-making. Includes two aspects: one is the choice and training of succession; second, the accumulation of social relation network and contacts to inherit. Second, the inheritance of decision-making to rights transition phase. Mainly includes three aspects: one is familiar with the whole process of the business, accumulates work experience; two, is fully empowered to make decisions, establish credibility; three, is bo form their own team, form his own brain trust. Third,formally completed handover stage. Also includes three aspects: one is the choice of transfer timing; second is the transition of ownership and managerial authority smoothly; three, is inherit the corporate culture of family[4].

\section{B. Select and cultivate successor}

Successor selection is the core and key of intergenerational inheritance, select and cultivate proper heir has a crucial effect to the sustainable development and growth of enterprise.

\section{1) The choice of a successor}

The choice of successor is the first step of power transmission in family enterprises, divided into family enterprise internal successor selection and external selection of professional managers. Most private family enterprises in Quanzhou still is given priority to internal selection, but due to the number of children in the family less and less, the selection of successors scope is narrow, the probability of success in not high, which can't meet the needs of the enterprise long-term development. On the career of inheritance, should not is to point to specific individuals, but all people, suggested that private business owners should look good moral character, excellent leadership, entrepreneurial passion and dream as the choice of successor ultimate standard, and should not sustain only by blood relationship.

\section{2) The cultivation of the successor}

For the cultivation of the internal successors mainly has two aspects: one is practice education, let the successor participate grassroots work time, delegate to solve realistic problems in the enterprise, and to accumulate experience and growth experience. Secondly, the knowledge education, let the successor to study in the universities,accept professional knowledge and advanced management idea, and improve the level of culture and ability accordingly.

The training of external professional managers there are two main ways: one is to become members of the family, became the public relations into a personal relationship, which may achieve by way of marriage, recognize nominal kinship, etc; The second is incentives to attract and retain foreign talent, including salary, career development opportunity, give the shares, and so on[5].

\section{Deal with the contradiction of management rights and property rights}

Ambiguous property rights and management rights of family business and has been a big obstacle to sustainable development of it. In the process of "second venture", the family enterprises need more professional talents, and if the family member companies too much of the corporate management position will affect the enterprise talent introduction. How to balance the contradiction between managerial authority and stock rights is one of the key factors of a successful transmission in the "second venture".

\section{Pay attention to the inheritance and build network}

Family business network of inheritance is a gradual process.

The inheritance of relationship network has two main parts from internal and external: internal, should pay attention to the communication and fusion with elders and core backbone.Elders and backbone is the key node to the inheritance of family enterprise, they control most of the resources and contacts, act the very major role in the enterprise. External, customers, suppliers, distributors, is the trade partners of enterprise, they are independent of the enterprise, and work closely with it, their informal relationships of enterprise also plays a major role.

Relational network construction is not only apply mechanically, but to comb and rebuild, to interaction and fusion between the two generations, and optimize and integration the relational network, set up a new management team of successors itself.

\section{E. Variable bloodline for cultural heritage}

In Quanzhou, many family enterprises is one-sided understanding,in fact, the hardest thing of inheritance to realize is the enterprise culture, in most of the private family enterprise, the style and concept of founder tends to represent the enterprise culture. In the environment of second venture, the enterprise will face new opportunities and risks, but the enterprise culture is the biggest driving force that prompting companies and the enterprise together[6].

Therefore, the private family enterprises of Quanzhou should abandon the wrong ideas of bloodline, enterprise cultural heritage is the key to inheritance.

\section{CONCLUSION}

Heald above, intergenerational inheritance of family enterprises, connected life extension directly, and concerned economic development of Quanzhou in the future. In the environment of "second venture", it will brings opportunities and challenges to intergenerational inheritance, expect the family enterprises to seize the opportunity, achieving the inheritance. 


\section{REFERENCES}

[1] JunSheng Duo,sheng-hua jia. Why estate evergreen - entrepreneur individual level family enterprise recognition [J] the intergenerational inheritance factor, management world, 2008 (9) : 105-117

[2] zhang bing. Family business intergenerational inheritance pattern research [D]. Zhejiang university, 2004

[3] Huang Jingyang. Second venture of small and medium-sized enterprises of quanzhou research [D]. Xiamen university, 2001
[4] Liao Renkui. Second startup perspective of family enterprise inheritance research [D]. Southwest national university, 2008

[5] liang-zhong luo. Family business succession management research in China [J]. Productivity research, 2009 (1) : 144-146

[6] Pan Junxu, jiong wu. Research on the question of family enterprises in our country inheritance review [J]. Journal of enterprise vitality, $2011(8): 88-91$ 